\title{
BMJ Open Citizen engagement initiatives in precision health in the European Union member states: a scoping review
}

\author{
Angelo Maria Pezzullo (1D , ${ }^{1}$ Michele Sassano (D) , ${ }^{1}$ Ilda Hoxhaj (D) , ${ }^{1}$ \\ Roberta Pastorino (D) ,2 Stefania Boccia (1) 1,2
}

To cite: Pezzullo AM, Sassano M, Hoxhaj I, et al. Citizen engagement initiatives in precision health in the European Union member states: a scoping review. BMJ Open 2021;11:e045846. doi:10.1136/ bmjopen-2020-045846

- Prepublication history and additional supplemental material for this paper are available online. To view these files, please visit the journal online (http://dx.doi.org/10.1136/ bmjopen-2020-045846).

AMP and MS contributed equally.

Received 13 0ctober 2020 Accepted 24 June 2021

Check for updates

(C) Author(s) (or their employer(s)) 2021. Re-use permitted under CC BY-NC. No commercial re-use. See rights and permissions. Published by BMJ.

${ }^{1}$ Section of Hygiene, University Department of Life Sciences and Public Health, Università Cattolica del Sacro Cuore, Roma Italy

${ }^{2}$ Department of Woman and Child Health and Public Health - Public Health Area, Policlinico Universitario A. Gemelli IRCCS, Roma, Italy

Correspondence to

Dr Ilda Hoxhaj;

ilda.hoxhaj1@unicatt.it

\section{ABSTRACT}

Introduction Precision health requires citizens that are empowered to orient health decisions towards their personal values, aware of the benefits and risks, and committed to sharing their personal data to trustful institutions. Effective citizen engagement initiatives are fundamental for the success of a precision health approach.

Objective To provide an overview of citizen engagement initiatives in precision health in European Union (EU) member states.

Design Scoping review.

Methods The electronic databases PubMed, Web of Science, CINAHL and Embase were searched to include articles published in English. Furthermore, desk research was conducted in English, Dutch, French, Italian and Spanish. Articles or reports regarding ongoing initiatives of citizen engagement in precision health conducted in EU member states and published from January 2015 to July 2020 were considered eligible. A quality assessment of the retrieved entries using Critical Appraisal Skills Programme tool was conducted.

Results We identified nine documents, which reported eight ongoing citizen engagement initiatives, with substantial variability. Government agencies, nongovernmental organisations and scientific societies were the main organisers and funders. Most of the initiatives were conducted in the UK. Genomics was the most emphasised aspect of precision health in these initiatives. Among the identified initiatives, both in-person and digital means were reported.

Conclusion Our work provides an overview of current citizen engagement initiatives in the EU that can be useful for stakeholders interested in designing and developing precision health projects enriched by meaningful citizen participation.

PROSPERO registration number CRD42020193866.

\section{INTRODUCTION}

Precision health is a vision and approach to health and healthcare that aims to use the ever-growing quantity and quality of data about personal genome, lifestyle and environment to respond to the need for more precise treatments and prevention. ${ }^{1} \mathrm{~A}$ personalised approach to medicine envisions and requires citizens who are: (1) aware of

\section{Strengths and limitations of this study}

This scoping review, to our knowledge, is the first to identify and summarise ongoing citizen engagement initiatives in precision health in European Union (EU) member states.

- The strength of this scoping review is its comprehensive and extensive search in English of four electronic bibliographic databases, and additional search in Dutch, French, Italian and Spanish on the grey literature.

- This scoping review acknowledges the limitation of not including all the conducted initiatives in EU member states in precision health, since they might not be reported and publicly available.

the benefits and risks of genomic medicine, (2) committed to sharing their personal data to trustful institutions, and (3) empowered to orient health decisions towards their personal values. $^{2-5}$ The adoption of these attitudes and behaviours towards personalised health is undermined by the poor level of genetic literacy found among the general population $^{6-8}$ that has been considered as a significant barrier ${ }^{9}$ for the public acceptance of genetics and genomics advancement. Moreover, attitudes of the general public towards genomic data sharing differ largely across the world, and are substantially influenced by socioeconomic factors. ${ }^{10} 11$ Public involvement in health policymaking and governance in this field, however, has not been embraced by most healthcare organisations. ${ }^{12}$ Large amount of genomic and phenotypic data is required from millions of citizens to foster a more precise prevention: citizens have to be informed about the potential risks and benefits of their personal data, provide insights about their priorities, be engaged to feel that they are benefiting the entire society. ${ }^{13}$ Citizens must be informed on how their data contribute to the understanding of human health, and also need to be reassured that their 
contribution will bring no personal harm to them or their relatives. ${ }^{13}$ To respond adequately to citizens' demands, scientists and decision-makers need to gather information about public knowledge gaps, perceptions and attitudes. ${ }^{2}$ Generally speaking, the aim of citizen engagement is to increase the citizens' active participation in healthcare, shaping and guiding research and policymaking by setting up the priorities of health programmes. ${ }^{14} 15$ Effective citizen education and engagement initiatives, by providing and enhancing citizen participation, can be crucial to build trust and support evidence generation both for and with citizens. ${ }^{16}$ A review on public engagement initiatives on genomics and personalised medicine conducted in 2013, reported a growing number of public engagement exercises, mostly conducted outside the European Union (EU). ${ }^{17} \mathrm{~A}$ more recent scoping review found that only one-third of all initiatives reported public involvement in any capacity. ${ }^{18}$ While these activities are deemed essential to maintain public trust and improve research outcomes and equity, reporting of such initiatives is often scarce. ${ }^{18}$ Given the growing interest in more precise and data-driven approaches to health and healthcare in Europe, it is important to explore and understand the current scenario of citizen engagement initiatives in precision health in the context of the EU member states.

Citizen engagement is one of the focus of the European project 'European network staff eXchange for integrAting precision health in the health Care sysTems', that aims to design and promote innovative citizen engagement models. ${ }^{1}$ Our scoping review has been developed within this project, aiming to explore and analyse the publicly available documents related to citizen engagement that reported initiatives, in order to inform policymakers on the current landscape of citizen engagement initiatives in precision health in EU member states.

\section{METHODS}

We conducted and reported a scoping review in accordance with the Preferred Reporting Items for Systematic reviews and Meta-Analyses extension for Scoping Reviews checklist (online supplemental file 1). ${ }^{19}$

The protocol of this scoping review has been registered in the International Prospective Register of Systematic Reviews (PROSPERO; online supplemental file 2).

\section{Eligibility criteria}

The research question and eligibility criteria for inclusion in our work were formulated according to the PICO framework: ${ }^{20}$

$\mathrm{P}$ (population): European citizens living in EU member states.

I (intervention): initiatives, models or platforms, ongoing or concluded in 2020.

C (comparator): not applicable.

O (outcome): citizen engagement, participation, involvement or empowerment in precision health.
Based on the PICO framework, publicly available articles or reports regarding ongoing citizen engagement initiatives and, containing considerations on the preparation, development, or implementation of citizen engagement models were considered eligible. For the purpose of this article, we considered a 'citizen engagement initiative in precision health' any process, strategy or model initiated by public entities (governmental or non-governmental agencies, universities or scientific societies) with the aim of informing, involving, empowering or fostering citizens' participation in approaches to health and healthcare that leverage the use of personal data to inform a more precise decision-making. Several dimensions have been analysed, which aimed at engaging people as: individuals in relation to health treatments and issues; as citizens who consider the future promises of precision health; and as health policymakers or stakeholders to decide future precision health priorities. Considering that there is not a universal consensus around the definition of personalised medicine, or precision health, we included the terms 'genomic \personalised precision' and 'health\medicine' as reported by the original documents.

We included articles and reports published in English, French, Spanish, Dutch and Italian language. Commentaries, editorials, conference abstracts, reviews, clinical case reports, clinical case series and book chapters were excluded.

\section{Search strategy}

Two authors (AMP and IH) performed the search on PubMed, Web of Science, CINAHL and Embase electronic databases, using the following search terms and related synonyms: "citizen", "population", "community", "public", "engagement", "participation”, "involvement", "empowerment", "precision health", "precision medicine", "precision healthcare", "personalised medicine", "personalized healthcare", "initiative", "model", "platform" and "framework".

Search strategies for the four scientific electronic databases are provided in online supplemental file 3 .

In a second step, two authors (AMP and MS) performed desk research independently, exploring the grey literature through Google, Bing and Yahoo search engines, using the same search terms, which were then translated to Dutch, French, Italian and Spanish to retrieve documents written in languages other than English. Additionally, in order to retrieve additional reports, two authors (AMP and MS) explored the websites of EU institutional agencies, including the EU Commission, European Public Health Association and European Alliance for Personalised Medicine.

The search for both scientific and grey literature included documents, articles and reports published from 1 January 2015 to 20 July 2020. We limited our search to documents published in 2015 or after, considering that in 2015, the EU health ministries defined personalised medicine, in the Council conclusions on personalised medicine for patients. Furthermore, in 2015, the 
EU-funded project 'PerMed' defined developing awareness and empowerment as one of the five challenges of personalised medicine, in its report 'Shaping Europe's Vision for Personalised Medicine'. ${ }^{21}$

\section{Study selection and data extraction}

After the scientific literature search, the identified articles were uploaded to Mendeley software and duplicates were removed. The remaining articles were exported to Rayyan QCRI software, where two independent authors (AMP and $\mathrm{IH}$ ) performed the first screening based on titles and abstracts. The pertinent articles with full texts available were reviewed by three authors (AMP, MS and IH) and the articles satisfying the eligibility criteria were included in the scoping review. Furthermore, their reference lists were manually searched for any additional relevant publication.

Regarding the grey literature search, two authors (AMP and MS) searched for grey literature independently and selected documents of interest by screening them by title, headings, summary and abstract. A list with the potentially eligible documents was created in Excel and, subsequently, full texts of these documents were assessed against our inclusion criteria by two researchers (AMP and MS) independently. Eventually, a hand search of reference lists of included documents was performed.

For each of the included documents, we extracted the following data: first author; publication year; country, language; project name, coordinator and funder; covered topic, citizen engagement method, objective and participants' characteristics.

\section{Syntheses of results}

Articles were categorised according to the type of citizen engagement method, using Excel spreadsheets. Aggregate data were used to provide a qualitative synthesis of each reported citizen engagement method: digital tools, citizen forums, open discussions, participation in governing committees and audiovisual tools. Two researchers (MS and $\mathrm{IH}$ ) were involved in the data synthesis process and discrepancies will be resolved by consulting a third researcher (AMP). In order to analyse the level of public participation in the identified citizen engagement initiatives, we used the International Association of Public Participation (IAP2) spectrum of public participation ${ }^{22}$ that classifies public participation processes based on their goals: from information/consultation (low level of impact on the decision-making) to involvement (medium level) to collaboration/empowerment (high level).

\section{Quality assessment}

We assessed the methodological quality of the included scientific articles using the Critical Appraisal Skills Programme (CASP) checklist for qualitative studies. ${ }^{23}$ This validated tool contains 10 questions about the objectives, appropriateness of study design and qualitative methods, eligibility and selection criteria, data collection strategy, researcher-participant relationship, ethical aspects, data analysis, statement of findings and value of the findings. Three authors (AMP, MS and
$\mathrm{IH}$ ) performed the quality assessment independently and any disagreement was resolved through discussion.

\section{Patient and public involvement}

Patient and the public were not involved in this study.

\section{RESULTS}

The study screening and selection process is reported in details in figure 1 . The scientific and grey literature search led to the identification of a total number of 1411 records. After removal of duplicates, 1102 records were screened by title, headings, summary, abstract or table of content, according to our eligibility criteria. Then, the full text of 91 records were carefully read. Finally, we included in our scoping review nine documents, four of which were retrieved through scientific literature search ${ }^{24-27}$ and five were identified through grey literature search. ${ }^{27-31}$ Articles retrieved by the scientific literature search were of qualitative study designs. The main characteristics of the included initiatives are reported in table 1.

The identified documents were published between 2015 and 2020 and reported eight initiatives. Six initiatives $(75 \%)$ were developed in the UK, ${ }^{24-29}$ one $(12.5 \%)$ in Spain ${ }^{30}$ and one (12.5\%) in Belgium. ${ }^{31}{ }^{32}$ Six initiatives $(75 \%)$ were conducted at the national level, ${ }^{25-28} 3031$ one initiative had a more local focus ${ }^{29}$ and the other one was carried out at international level. ${ }^{24}$

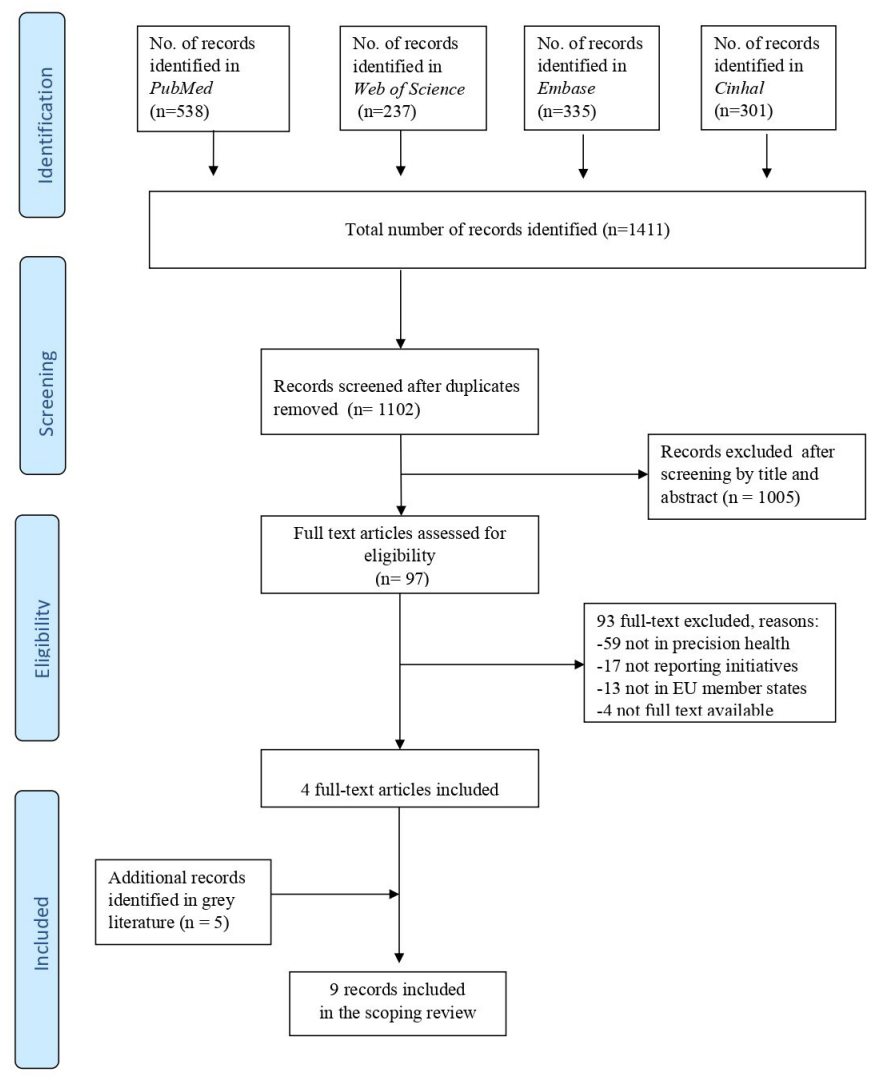

Figure 1 Flow chart of the selection and screening process in the scoping review. 


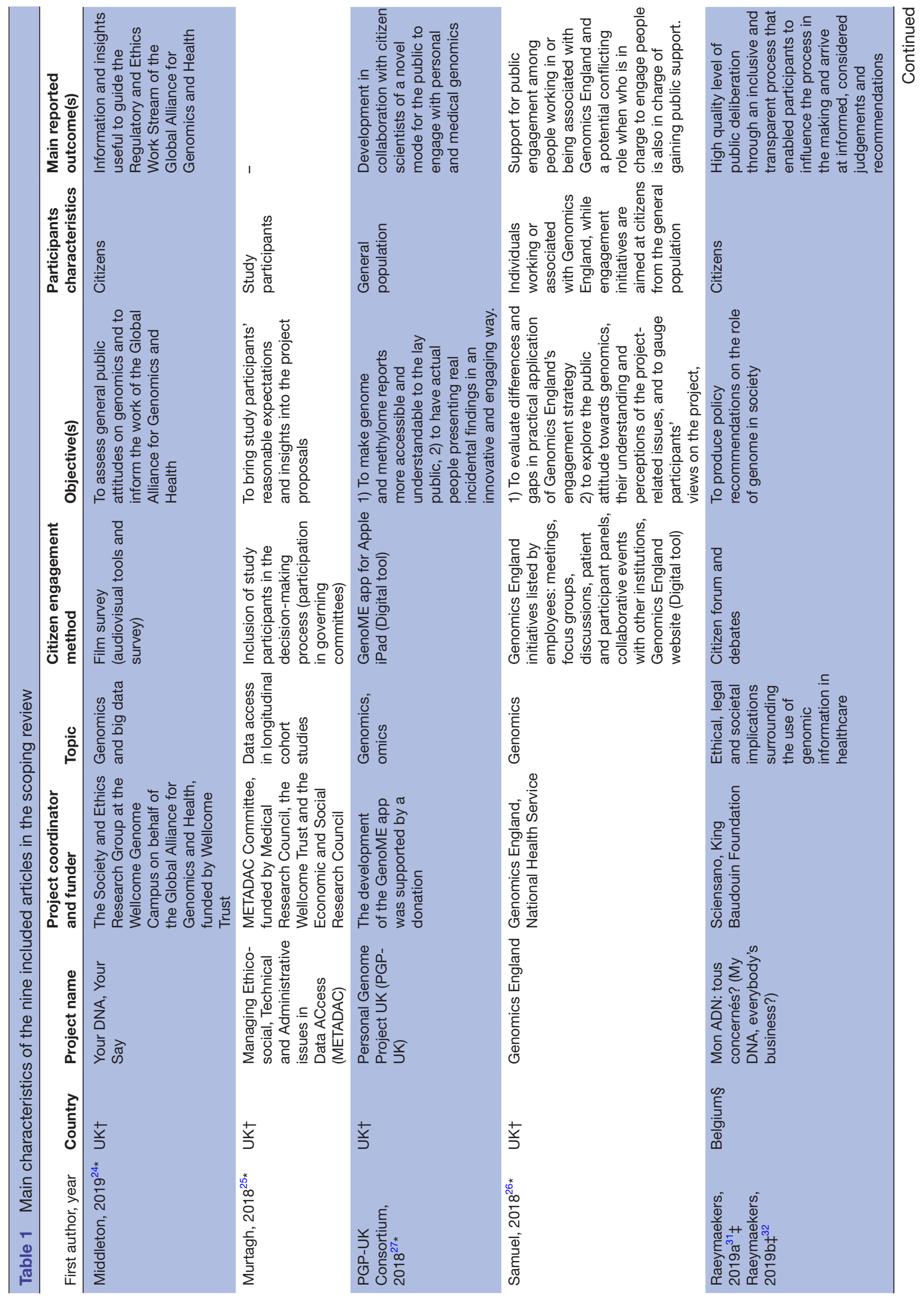




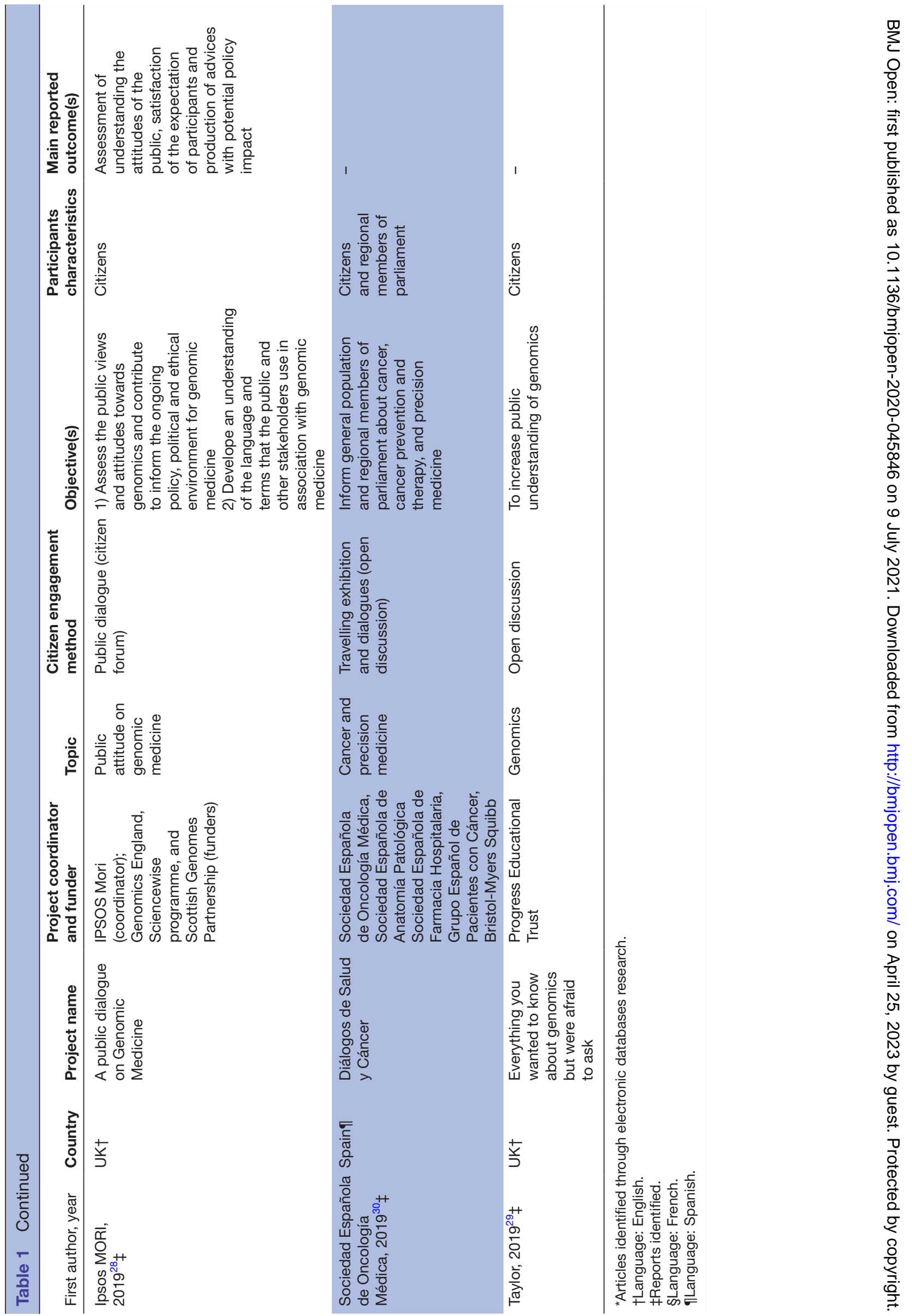


Regarding the main topic, most initiatives $(75 \%, \mathrm{n}=6)$ focused on genomics or omics sciences, ${ }^{2426-293132}$ while one $(12.5 \%)$ dealt more specifically with issues surrounding the access to personal health data for scientific, medical and/or policy planning purposes, ${ }^{25}$ and one $(12.5 \%)$ concerned cancer and the role of precision medicine in this field. ${ }^{30}$ In particular, the focus of genomics involvement activities were expectations, understanding and attitudes towards willingness to donate personal data, secondary access to data, and ethical, legal, social implications of genomics in society.

One document addressed the engagement of participants of research studies in a data access governance committee, ${ }^{25}$ whereas other seven reported initiatives that were directed to the general population. ${ }^{24}{ }^{27-32}$ Six initiatives were aimed at a wider engagement by including in the process also policymakers, researchers and experts, and industry. ${ }^{25} 26$ 28-32

\section{Quality assessment}

The quality assessment of the four scientific articles included in our review, using CASP checklist for qualitative studies, is reported in table 2.

In particular, all fields evaluated by the aforementioned checklist were deemed as satisfactory for most included studies. The only exception is represented by the item investigating if the relationship between the researcher and participants has been adequately taken into account, in particular in terms of critical examination of the researcher's role, potential bias and influence during the formulation of the research questions and data collection, which was evaluated not satisfactory for two studies. ${ }^{25} 27$ Hence, study findings were evaluated 'valuable' for all the included articles, for the appropriate contextualisation of results in the landscape of current literature and the considerations about applications of findings.

\section{Citizen engagement methods and aims}

The included initiatives described a variety of citizen engagement methods in various aspects of precision health. Each method is discussed separately in the next paragraphs.

\section{Digital tools}

Three initiatives used digital tools as means to achieve citizen engagement, two used web platforms and apps as the sole means to connect with citizens, ${ }^{24}{ }^{27}$ while one used blended (in-person and online) methods. ${ }^{26}$ The website of Genomics England initiative, providing informative materials for public consultation, was considered of utmost importance to obtain public support needed to achieve the final objective of 100,000 Genome Project. ${ }^{26}$ Additionally, in order to gain public trust, focus groups, meetings, patient panels, public events and discussions were suggested as the key elements of public engagement and involvement in precision medicine. ${ }^{26}$ Samuel and colleagues also highlighted the support for public engagement among people working in or being associated with Genomics England and a potential conflicting role when who is in charge to engage people is also in charge of gaining public support. ${ }^{26}$ Another tool developed to make more accessible and understandable to the public information regarding genome and methylome, is the GenoME app. This free access app enables people to explore the genetic code, including information for ancestry, eye colour, health, smoking and age. The main purpose of this app was to have actual people presenting real incidental findings in an innovative and engaging way. The GenoME app is reported as a novel mode for the public to engage with personal and medical genomics. ${ }^{27}$

\section{Citizen forums}

The citizen forum 'My DNA, everybody's concern' in Belgium, concluded that citizens should have control over the use of genomic information to protect their privacy, and this has to be taken into account by policymakers. ${ }^{31} 32$ 'A public dialogue on Genomic Medicine' was a citizen forum, commissioned for Ipsos MORI by Genomics England and others, mainly aimed at assessing public views and attitudes to genomics, informing the ongoing political environment and developing an understanding of the language and terms that the public and other stakeholders use in association with genomic medicine. This work detailed citizens' views, concerns and aspirations towards genomic medicine, and also giving suggestions on how to operationalise them. ${ }^{28}$ The two citizen forums were the only projects to report independent evaluation processes. ${ }^{28} 3132$ The Genomics England citizen forum evaluation was conducted by a consultancy firm specialising in socioeconomic analyses; they concluded that the citizen forum was able to meet the predefined objectives, satisfy the participants' expectations and have policy impact. ${ }^{33}$ The Sciensano citizen forum evaluation process was led by university researchers and reported a high quality level of public deliberation through an inclusive and transparent process that enabled participants to influence the process in the making and arrive at informed, considered judgements and recommendations. ${ }^{34}$

\section{Open discussions}

The initiative Dialogos de Salud y Cancer ('Cancer and Health Dialogues') consisted of a travelling exhibition that aimed at increasing participants' knowledge about cancer and precision medicine through virtual reality, questions and answers, and interactive films. ${ }^{30}$ Moreover, the report of the Progress Educational Trust open discussion underlines the need for more public education regarding the benefits and limitations of genomic medicine..$^{29}$

\section{Participation in governing committees}

Instead, the study developed within the Managing Ethicosocial, Technical and Administrative issues in Data ACcess (METADAC) committee, a multiagency multistudy data access structure that serves several of the major cohort studies in UK, describes the involvement of study participants in the decision-making process as a way to improve study outcomes and meet the expectations and values of 


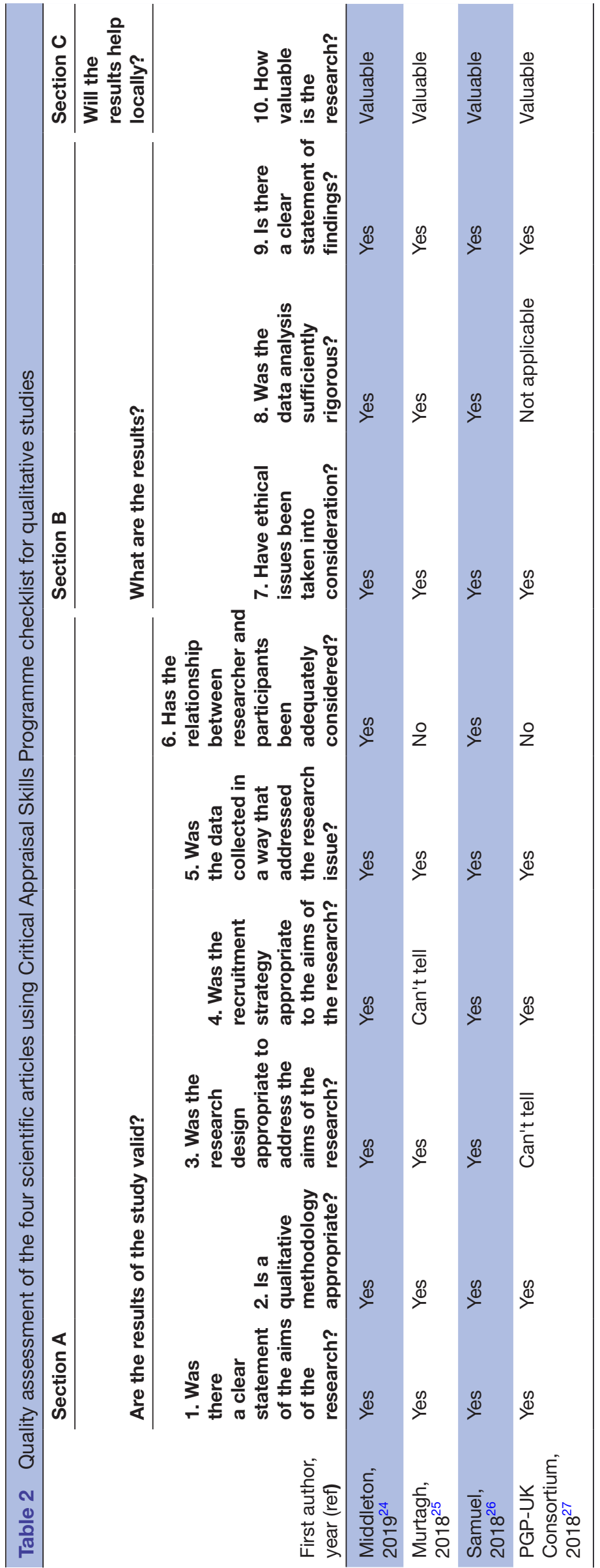

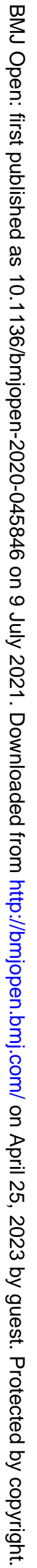


participants, with their involvement growing together with and according to their knowledge level. ${ }^{25}$

\section{Audiovisual tools and surveys}

The project 'Your DNA, your say', part of the Regulatory and Ethics Work Stream of the Global Alliance for Genomics and Health, was an online survey used as a means for the assessment of public attitudes towards donating and sharing own genomic information and data, with the support of short videos that were aimed at both helping study participants understand and answer the questions of the questionnaire and raising awareness about genomics and big data. The authors of this project reported on the profile of people unwilling to donate their genomic information: more likely to be older, of lower education background, childless and identifying themselves as part of an ethnic minority. ${ }^{24}$

\section{Extent of public participation in the projects}

A variable degree of public deliberation, that ranges from simpler open discussions ${ }^{29} 30$ to structured citizen forums ${ }^{283132}$ is described in most initiatives. The level of public participation was:

- Low at five initiatives, such as: open discussions ${ }^{29} 30$ aimed at informing the population and increasing the literacy of citizens; 'the public dialogue on genomic medicine', ${ }^{28}$ and the corporate strategy of Genomics England $^{26}$ aimed at consulting the citizens to establish current public understanding; and Your DNA, your say $^{24}$ that aimed at both informing and consulting the citizens.

- Medium at two initiatives: inclusion in the METADAC committee $^{25}$ and the Personal Genome Project UK GenoME app ${ }^{27}$ aiming at involving the citizens in improving accessibility to data and data sharing.

- High, at two initiatives, which through the investigation of public opinion and attitudes gathered useful information to produce citizen-oriented recommendations to influence policy choices. ${ }^{26} 283132$

\section{DISCUSSION}

In the present work, we provided an overview of ongoing citizen engagement activities in precision health in the EU member states. We identified eight engagement initiatives, ongoing or recently concluded, that varied in the way through which citizen engagement occurred and was reported. The engagement methods used in the identified initiatives were open discussions, citizen forums, digital tools, such as tablet apps and online platforms, survey with audiovisual tools and advisory board involvement. The majority of these initiatives were aimed at gathering citizen perspectives to inform policymaking, or at establishing current public understanding on precision health, mostly with a focus on genomics.

Prior to 2015, reported citizen engagement initiatives worldwide included quantitative ${ }^{10} 173536$ and qualitative surveys, ${ }^{11} 18$ public deliberation models, ${ }^{1736} 37$ focus groups, ${ }^{17}{ }^{36}{ }^{38-40}$ science cafés, $^{41}$ online platforms ${ }^{42}$ and boards participation. ${ }^{17} 363840$ The increasing number of citizen engagement initiatives in recent years in EU member states is likely due to a growing interest by national and European authorities in precision health, and other personalised approaches to health, evidenced by the development of national plans by some countries $^{4344}$ and also by the foundation in 2016 of the International Consortium for Personalised Medicine. ${ }^{45}$

The main topic of most of the initiatives included in our scoping review was genomics, which together with the other omics sciences, set up the basis of personalised approaches to health. This was expected since previous literature has examined the main topic of public involvement initiatives and found a similar focus on understanding and attitudes towards genomics. ${ }^{17}$ Moreover, genomic techniques are commonly associated with the terms 'precision' and 'personalised' and these terms were used in the search strategy.

We reported high variability for the included projects in citizen engagement methods, aims and degree of public participation. This, in part, reflects the general diversity in components and aims of citizen engagement. ${ }^{46}$ We report different levels of public participation in the projects ranging from low ${ }^{24} 2930$ to high. ${ }^{28} 3132$ The highest degree of public participation was reached through the citizen forum, that represents a way to create practical policy output with involvement of citizens, experts, stakeholders and policymakers. ${ }^{32}$ This collaborative and deliberative approach offers an alternative to a market-based approach or authoritarian approach where one actor in the field of genomics might determine the entire playbook. ${ }^{47}$ According to Manafò et al, the degree of public deliberation is strictly related to time, knowledge and funds needed for public engagement initiatives. ${ }^{15}$ Six out of eight initiatives included in this scoping review had a lowto-medium level of public deliberation that may be due to a lack of resources invested in citizen engagement activities.

In our review, many of the citizen engagement activities were conducted through digital means. There is contrasting evidence regarding the use of digital means in public involvement activities: Etchegary and Wilson reported in 2013 only one initiative that used digital means to engage with citizens, ${ }^{17}$ while in the scoping review on public involvement in genomics research by Nunn et al, 7 out of 32 initiatives used online tools, ${ }^{18}$ hence this may reflect an evolution towards a more conspicuous role of digital means in citizen engagement activities.

We note that outcomes of the citizen engagement initiatives are scarcely defined and reported, and only two initiatives $^{2831} 32$ were independently evaluated in the process. ${ }^{33} 34$ This is in line with a review on public participation in healthcare priority setting that found that engagement exercises are rarely formally evaluated. ${ }^{48}$ In our scoping review, public consultations were typically made una tantum or at the beginning of a broader precision health project. Most of the identified initiatives engaged citizens at the consultation level on the IAP2 spectrum, by generally asking for input at set points in the process and not providing an ongoing opportunity for input. Therefore, there is the need to elaborate initiatives 
that engage citizens in all the levels of the IAP2 spectrum. This approach will give them the opportunity to provide inputs and receive feedback on how these inputs influenced all the aspects of decision-making, throughout the entire process. Citizen engagement initiatives can be used to evaluate the points of view of citizens toward novel technologies and projects to ascertain their acceptability, potential ethical issues, and challenges in implementation and scalability, while raising awareness and stimulating ownership of the decision-making processes. ${ }^{15}$

The quality of citizen engagement initiatives remains a concern for the data gathering and interpretation. ${ }^{49}$ Particular attention should be given to the facilitators and barriers to the involvement of citizens in these initiatives, like reimbursement policies or education and training opportunities. ${ }^{16}$ In 2015, Budin-Ljøsne and Harris denounced that the expectation of a high degree of commitment by the citizens in personalised medicine was not matched by an adequate consideration of the educational, technological and socioeconomic barriers in place. ${ }^{2}$ Efforts in citizen engagement are meant to ensure that these hurdles are addressed and overcome.

Our findings should be interpreted in the light of some limitations and strengths. We recognise as a limitation to our work that citizen engagement initiatives may not be reported publicly, indicating the possibility of publication bias. Considering that reports of citizen engagement initiatives in the EU member states could be available in many national languages and published through a broad range of different media, we used a comprehensive and multilanguage grey literature search strategy and a careful screening of the references. In addition, due to the broad search query, we might have not identified initiatives focused on using environmental and lifestyle data.

To our knowledge, this is the first review concerning citizen engagement initiatives in precision health in the EU member states. Our study has also other important strengths: (1) the comprehensiveness of our search, including four bibliographic databases and different strategies to search for grey literature; (2) the inclusivity of our search string allowed us to include all the relevant documents, regardless of the definition used; and (3) the good quality of the included documents.

With reference to policy and practical implications, considering our findings, it is of utmost importance to include the literacy and engagement of citizens as an emerging policy priority in the national governmental strategies and plans. Policy development process should directly include citizens in different steps of the policy cycle, that could enable the implementation in a more effective and efficient way. Therefore, they should be engaged, particularly, in the initial step of identifying policy priorities, as well as in the policy planning and implementation phases.

Citizens should also participate in research endeavour, such as the actual knowledge production, being involved in the definition, collection, use and validation of scientific results. There is a need to build citizens' capabilities, for participatory and deliberative practices of policy elaboration and service delivery; therefore, their educational needs and socioeconomic hurdles should be properly addressed. Particular attention should be paid to policy challenges and gaps, as well as to facilitators and barriers to the involvement of citizens in these initiatives.

\section{CONCLUSION}

Our work provided an overview of the citizen engagement initiatives in the EU member states and identified an increased interest in citizen engagement in precision health with an increased use of digital means. This work might contribute to inform European stakeholders involved in designing and developing precision health projects enriched by meaningful citizen participation. In fact, a shift towards more precise and personalised health and healthcare is considered a priority by the EU and requires strong and engaged citizens to ensure it.

Acknowledgements The authors would like to thank Maaike Droogers, from the European Public Health Association, for her valuable technical help in the search strategy.

Contributors SB conceptualised the research questions and the search strategy, contributed to the final version of the manuscript and supervised the research project. AMP, MS and IH performed the research in the electronic databases and independently conducted the screening and study selection phase and the quality assessment of the included studies. AMP and MS both wrote the background, and discussion section, IH wrote the methods section, IH and MS both wrote the results section. RP supervised the search strategy and the interpretation of the results and critically revised the manuscript preparation process. All authors read and approved the final manuscript.

Funding This research is supported by the European Network Staff Exchange for Integrating Precision Health in the Healthcare Systems project (Marie SkłodowskaCurie Research and Innovation Staff Exchange no. 823995).

Competing interests None declared.

Patient consent for publication Not required.

Provenance and peer review Not commissioned; externally peer-reviewed.

Data availability statement All data relevant to the study are included in the article or uploaded as supplemental information.

Supplemental material This content has been supplied by the author(s). It has not been vetted by BMJ Publishing Group Limited (BMJ) and may not have been peer-reviewed. Any opinions or recommendations discussed are solely those of the author(s) and are not endorsed by BMJ. BMJ disclaims all liability and responsibility arising from any reliance placed on the content. Where the content includes any translated material, BMJ does not warrant the accuracy and reliability of the translations (including but not limited to local regulations, clinical guidelines, terminology, drug names and drug dosages), and is not responsible for any error and/or omissions arising from translation and adaptation or otherwise.

Open access This is an open access article distributed in accordance with the Creative Commons Attribution Non Commercial (CC BY-NC 4.0) license, which permits others to distribute, remix, adapt, build upon this work non-commercially, and license their derivative works on different terms, provided the original work is properly cited, appropriate credit is given, any changes made indicated, and the use is non-commercial. See: http://creativecommons.org/licenses/by-nc/4.0/.

\section{ORCID iDs}

Angelo Maria Pezzullo http://orcid.org/0000-0002-8252-4654

Michele Sassano http://orcid.org/0000-0002-3158-1827

Ilda Hoxhaj http://orcid.org/0000-0001-7086-2456

Roberta Pastorino http://orcid.org/0000-0001-5013-0733

Stefania Boccia http://orcid.org/0000-0002-1864-749X 


\section{REFERENCES}

1 Boccia S, Pastorino R, Mariani M. The European network staff eXchange for integrAting precision health in the health care sysTems (exact): a Marie Curie research and innovation staff eXchange (rise) project. Epidemiol Biostat Public Health 2019;16.

2 Budin-Ljøsne I, Harris JR. Ask not what personalized medicine can do for you--ask what you can do for personalized medicine. Public Health Genomics 2015;18:131-8.

3 The ICPerMed vision for 2030, 2019. Available: https://www. icpermed.eu/media/content/Vision_Paper_2019.pdf [Accessed 14 Feb 2020].

4 Boccia S, Mc Kee M, Adany R, et al. Beyond public health genomics: proposals from an international working group. Eur J Public Health 2014;24:877-9.

5 Acting together: a roadmap for sustainable healthcare, 2015. Available: https://sustainable-healthcare.com/content-assets/ uploads/2016/11/EU-White-Paper-Full-version-FINAL-VERSION-.pdf [Accessed 14 Feb 2020].

6 Chapman R, Likhanov M, Selita F, et al. New literacy challenge for the twenty-first century: genetic knowledge is poor even among well educated. J Community Genet 2019;10:73-84.

7 Hoxhaj I, Stojanovic J, Boccia S. European citizens' perspectives on direct-to-consumer genetic testing: an updated systematic review. Eur J Public Health 2020:ckz246.

8 Calabrò GE, Sassano M, Tognetto A, et al. Citizens' Attitudes, Knowledge, and Educational Needs in the Field of Omics Sciences: A Systematic Literature Review. Front Genet 2020;11:1261.

9 Rafiq M, lanuale C, Ricciardi W, et al. Direct-To-Consume genetic testing: a systematic review of European guidelines, recommendations, and position statements. Genet Test Mol Biomarkers 2015;19:535-47.

10 Shabani M, Bezuidenhout L, Borry P. Attitudes of research participants and the general public towards genomic data sharing: a systematic literature review. Expert Rev Mol Diagn 2014;14:1053-65.

11 Riordan F, Papoutsi C, Reed JE, et al. Patient and public attitudes towards informed consent models and levels of awareness of electronic health records in the UK. Int $\mathrm{J}$ Med Inform 2015;84:237-47.

12 Ocloo J, Matthews R. From tokenism to empowerment: progressing patient and public involvement in healthcare improvement. BMJ Qual Saf 2016;25:626-32.

13 Middleton A. Society and personal genome data. Hum Mol Genet 2018;27:R8-13.

14 Etchegary H, Green J, Parfrey P, et al. Community engagement with genetics: public perceptions and expectations about genetics research. Health Expect 2015;18:1413-25.

15 Manafò E, Petermann L, Vandall-Walker V, et al. Patient and public engagement in priority setting: a systematic rapid review of the literature. PLoS One 2018;13:e0193579.

16 Petersen C, Austin RR, Backonja U, et al. Citizen science to further precision medicine: from vision to implementation. JAMIA Open 2020;3:2-8.

17 Etchegary $\mathrm{H}$, Wilson $\mathrm{B}$. Bringing personalized medicine to the community through public engagement. Per Med 2013;10:647-59

18 Nunn JS, Tiller J, Fransquet P, et al. Public involvement in global genomics research: a scoping review. Front Public Health 2019;7:79.

19 Tricco AC, Lillie E, Zarin W, et al. PRISMA extension for scoping reviews (PRISMA-ScR): checklist and explanation. Ann Intern Med 2018;169:467-73.

20 O'Connor D, Green S, Higgins JP. Defining the review question and developing criteria for including studies. In: Cochrane Handbook for systematic reviews of interventions: cochrane book series. . Wiley Online Library, 2008: 26. 81-94.

21 PerMed. SRIA (Strategic Research and Innovation Agenda) Shaping Europe's Vision for Personalised Medicine, 2015. Available: http:// www.permed2020.eu/ media/PerMed SRIA.pdf [Accessed Jun 2021].

22 International Association for Public Participation. lap2 spectrum of public participation, 2018. Available: https://cdn.ymaws.com/ www.iap2.org/resource/resmgr/pillars/Spectrum_8.5x11_Print.pdf [Accessed 23 Aug 2020].

23 Critical Appraisal Skills Programme. Casp qualitative checklist, 2018. Available: https://casp-uk.net/casp-tools-checklists/ [Accessed 22 Jun 2020].

24 Middleton A, Milne R, Thorogood A, et al. Attitudes of publics who are unwilling to donate DNA data for research. Eur J Med Genet 2019;62:316-23.

25 Murtagh MJ, Blell MT, Butters OW, et al. Better governance, better access: practising responsible data sharing in the METADAC governance infrastructure. Hum Genomics 2018;12:24.
26 Samuel GN, Farsides B. Genomics England's implementation of its public engagement strategy: blurred boundaries between engagement for the United Kingdom's 100,000 genomes project and the need for public support. Public Underst Sci 2018;27:352-64.

27 PGP-UK Consortium. Personal genome Project UK (PGP-UK): a research and citizen science hybrid project in support of personalized medicine. BMC Med Genomics 2018;11:108.

28 Ipsos M. A public dialogue on genomic medicine: time for a new social contract?, 2019. Available: https://www.ipsos.com/ipsos-mori/ en-uk/public-dialogue-genomic-medicine-time-new-social-contractreport [Accessed 28 Jul 2020]

29 Taylor E. Everything you wanted to know about genomics but were afraid to ask. BioNews, 2019. Available: https://www.bionews.org.uk page_144882 [Accessed 28 Jul 2020].

30 Sociedad Española de Oncología Médica. SEOM recorre España para informar Y sensibilizar a la Sociedad sobre El cáncer Y La medicina de Precisión. Revista SEOM, 2019. Available: https:// seom.org/seomcms/images/stories/recursos/revista_123 pub.pdf [Accessed 28 Jul 2020].

31 Raeymaekers P, Teller M. Mon ADN, tous concernés? L'avis des citoyens sur l'utilisation des données du génome dans les soins de santé. Fondation Roi Baudouin, 2019. Available: https://www.kbs-frb. be/fr/Activities/Publications/2019/20190225PP2 [Accessed 28 Jul 2020].

32 Raeymaekers P, Teller M. La connaissance du génome influence les soins de santé: les citoyens demandent une politique pour l'avenir. Fondation Roi Baudouin, 2019. Available: https://www.kbs-frb. be/fr/Activities/Publications/2019/20190717PP [Accessed 28 Jul 2020].

33 MacGillivray A. Evaluation of a public dialogue on genomic medicine: time for a new social contract? Ursus consulting, 2019. Available: https://www.genomicsengland.co.uk/wp-content/uploads/2019/07/ Sciencewise-public-dialogue-evaluation-report.pdf [Accessed 06 Sep 2020].

34 Marien S, Felicetti A. Citizen forum on the use of genome information in health care: an assessment of the quality of the process. $\mathrm{Ku}$ Leuven, 2019. Available: https://soc.kuleuven.be/centre-for-politicalresearch/demoinno/files/citizens-reporten-executive-reportnl-fr.pdf [Accessed 06 Sep 2020].

35 Finegold $\mathrm{P}$, Mathieson K, Holmes L, et al. Is the UK public ready for genetic medicine? Per Med 2008;5:65-76.

36 Lemke AA, Wolf WA, Hebert-Beirne J, et al. Public and Biobank participant attitudes toward genetic research participation and data sharing. Public Health Genomics 2010;13:368-77.

37 Burgess M, O'Doherty K, Secko D. Biobanking in British Columbia: discussions of the future of personalized medicine through deliberative public engagement. Per Med 2008:5:285-96.

38 McCarty CA, Chisholm RL, Chute CG, et al. The eMERGE network: a consortium of biorepositories linked to electronic medical records data for conducting genomic studies. BMC Med Genomics 2011;4:13.

39 Buseh AG, Underwood SM, Stevens PE, et al. Black African immigrant community leaders' views on participation in genomics research and DNA biobanking. Nurs Outlook 2013;61:196-204.

40 Hartzler A, McCarty CA, Rasmussen LV, et al. Stakeholder engagement: a key component of integrating genomic information into electronic health records. Genet Med 2013;15:792-801.

41 Ahmed S, DeFino MC, Connors ER, et al. Science cafés: engaging scientists and community through health and science dialogue. Clin Trans/ Sci 2014;7:196-200.

42 Kirkpatrick BE, Riggs ER, Azzariti DR, et al. GenomeConnect: matchmaking between patients, clinical laboratories, and researchers to improve genomic knowledge. Hum Mutat 2015;36:974-8.

43 Boccia S, Federici A, Siliquini R. Implementation of genomic policies in Italy: the new national plan for innovation of the health system based on omics sciences. Epidemiol Biostat Public Health 2017;14

44 Aviesan. Genomic medicine France 2025, 2015. Available: https:// solidarites-sante.gouv.fr/IMG/pdf/genomic_medicine_france_2025. pdf [Accessed 06 Sep 2020].

45 International Consortium for personalised medicine (ICPerMed). Available: http://www.icpermed.eu [Accessed 06 Sep 2020]

46 Gaventa J, Barrett G. Mapping the outcomes of citizen engagement. World Dev 2012;40:2399-410.

47 Parkinson J. Deliberating in the real world: problems of legitimacy in deliberative democracy. Oxford University Press, 2006.

48 Mitton C, Smith N, Peacock S, et al. Public participation in health care priority setting: a scoping review. Health Policy 2009;91:219-28.

49 Figueiredo Nascimento S, Cuccillato E, Schade S. Citizen engagement in science and policy-making. Eur 28328 en. Available: https://ec.europa.eu/jrc/communities/sites/jrccties/files/mc10_rio_ siolopez_mobility_reading.pdf [Accessed 28 Jul 2020]. 